\title{
Design and Implementation of a Novel Multilevel DC-AC Inverter
}

\author{
Priyanka $^{1}$, Nagabhushan ${ }^{2}$ \\ ${ }^{1}$ M. Tech student, Department of EEE, PDA College of Engineering Gulbarga, India \\ ${ }^{2}$ Professor, Department of EEE, PDA College of Engineering Gulbarga, India
}

\begin{abstract}
A novel multilevel DC-AC inverter is proposed in this paper. A seven level AC output voltage is generated using the proposed multilevel with the befitting gate signals design. The total harmonic distortion in the sinusoidal output voltage reduced using low pass filter. With the suggested multi-level inverter the switching losses and the voltage stress of power devices can be reduced. The operating principles of the proposed inverter and the voltage balancing method of input capacitors are discussed. Finally, a laboratory model of multilevel inverter with $400 \mathrm{~V}$ input voltage and output $220 V_{r m s} / 2 \mathrm{~kW}$ is enforced. $16 F 877 \mathrm{~A}$ PIC microcontroller is used to control the multilevel inverter with sinusoidal pulse-width modulation (SPWM).
\end{abstract}

Keywords: Multilevel inverter, DC to AC inverter, Microcontroller, MPPT.

\section{Introduction}

As a result of high technology development, the demand and the quality of electric power is higher than before. The qualification of power device and power conversion technique is advanced as there is an improvement in semiconductor technology. One of the power converters which can transform DC to AC is called inverter. Electrical equipment such as uninterruptible power supply, servo motor, air-conditioning systemare powered by an inverter and smart grid compose of renewable energy. To satisfy different demands and characteristic of loads, the output frequency and voltage have to change with different loads.

In recent years, the amount of power equipment required is increasing and hence there is a serious issue of harmonic pollution in power systems. Several standards and regulations have been formulated to limit quality of harmonics and power factor of electric equipment. Furthermore, the industry demand higher power applications, the specification of power device is higher. IGBT cannot operate at high frequency in spite of features such as high power rating and high voltage stress. And the design of IGBT gate driver is complicated. MOSFET is the appropriate component to operate at high frequency, but power rating is not as good as IGBT. To solve the problem, many different topology of multilevel use low rating component at high power application.

The purpose of multilevel topology is to reduce voltage rating of power switch. Therefore, it usually use at high power application. Low $\mathrm{dv} / \mathrm{dt}$, low input current distortion, and lower switching frequency can be obtained by combining output voltages in multilevel form. As a result of advantages of multilevel topology, several topologies have emerged in recent years.

A novel multilevel inverter is designed and implemented in this paper. The major feature of the proposed topology is the reduction of power components. The sinusoidal pulse-width modulation (SPWM) is used to control proposed circuit by 16F877A PIC microcontroller.

\section{Block Diagram}

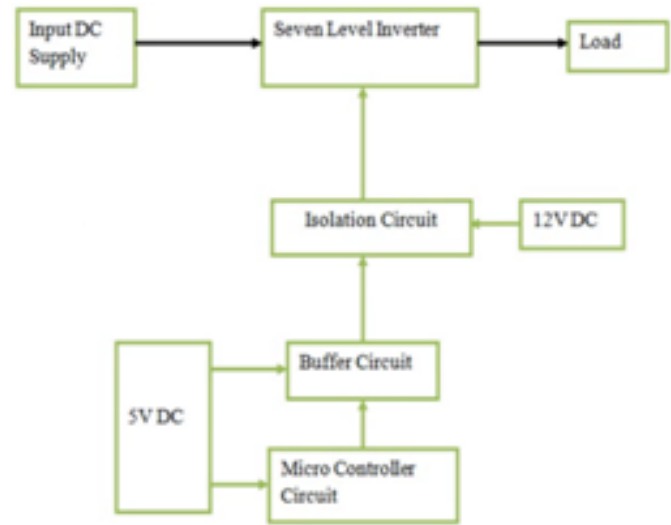

Figure 1: Block diagram of seven level inverter

1) Isolation Circuit: Damage to either of electrical circuit when one of them is under fault conditions can be prevented with the help of isolation circuit. High voltage and low voltage circuits can be isolated with this circuit. The isolation circuit is directly connected to seven-level inverter and a $12 \mathrm{~V} \mathrm{DC}$ is required to control the isolation circuit.

2) Microcontroller Circuit: The 16F877A PIC Microcontroller is used here. The microcontroller circuit is used to control the turning on and off of the switches of a seven level inverter. To control the microcontroller circuit we require a $5 \mathrm{~V} \mathrm{DC}$. The microcontroller circuit is connected to a seven level inverter via isolation circuit.

3) Load: Multilevel structure is usually used in inductive loads such as motor. Thus, this paper applies the proposed topology in inductive load. We get output $220 \mathrm{vrms} / 2 \mathrm{KW}$ across the load.

4) Buffer circuit: It is used to provide transformation ofelectrical impedance from one circuit to another. To control the buffer circuit we require a $5 \mathrm{~V} \mathrm{DC}$.

5) Input DC supply: We are providing a supply of $400 \mathrm{~V}$ dc input voltage which is connected to a seven level inverter. 


\section{International Journal of Science and Research (IJSR) \\ ISSN (Online): 2319-7064}

Index Copernicus Value (2015): 78.96 | Impact Factor (2015): 6.391

\section{Circuit Diagram of Proposed Seven Level Inverter Topology}

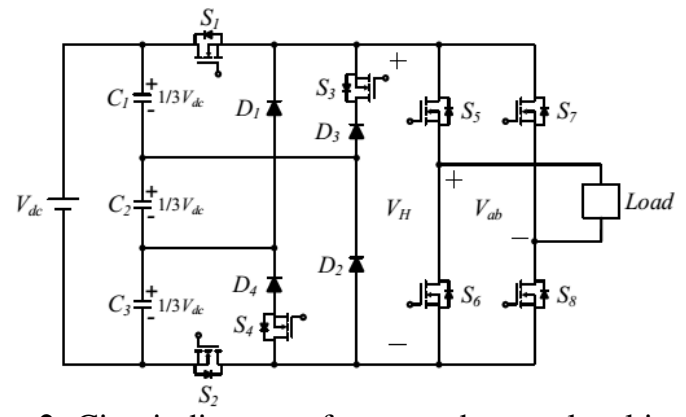

Figure 2: Circuit diagram of proposed seven-level inverter topology.

\subsection{Circuit Configuration}

Fig 2 shows the proposed novel topology used in the sevenlevel inverter. An input voltage divider is composed of three series capacitors $C_{1}, C_{2}$, and $C_{3}$. The divided voltage is transmitted to $\mathrm{H}$-bridge by four MOSFET, and four diodes. The voltage is send to output terminal by $\mathrm{H}$-bridge which is formed by four MOSFET. The proposed multilevel inverter generates seven levels AC output voltage with the appropriate gate signals design.

\subsection{Operating Principles}

The required seven voltage output levels $\left( \pm 1 / 3 V_{\mathrm{dc}}, \pm 2 / 3 V_{\mathrm{dc}}\right.$, $\left.\pm V_{\mathrm{dc}}, 0\right)$ are generated as follows:

1) To generate a voltage level $V_{\mathrm{o}}=1 / 3 V_{\mathrm{dc}}$, switch $S_{1}$ is turned on at the positive half cycle while the energy is provided by the capacitor $C_{1}$ and the voltage across $\mathrm{H}$ bridge is $1 / 3 V_{\mathrm{dc}}$. Then the switches $S_{5}$ and $S_{8}$ are turned on and thus the voltage applied to the load terminals is $1 / 3 V_{\mathrm{dc}}$. Fig. 3 shows the current path at this mode.

2) To generate a voltage level $V_{\mathrm{o}}=2 / 3 V_{\mathrm{dc}}, S_{1}$ and $S_{4}$ are turned on while the energy is provided by the capacitor $C_{1}$ and $C_{2}$ and the voltage across H-bridge is $2 / 3 V_{\mathrm{dc}}$, Then the switches $S_{5}$ and $S_{8}$ are turned on and thus the voltage applied to the load terminals is $2 / 3 V_{\mathrm{dc}}$. Fig. 4 shows the current path at this mode.

3) To generate a voltage level $V_{\mathrm{o}}=V_{\mathrm{dc}}, S_{1}$ and $S_{2}$ are turned on while the energy is provided by the capacitor $C_{1}, C_{2}$, and $C_{3}$ and the voltage across $\mathrm{H}$-bridge is $V_{\mathrm{dc}}$. Then the switches $S_{5}$ and $S_{8}$ are turned on and thus the voltage applied to the load terminals is $V_{\mathrm{dc}}$. Fig. 5 shows the current path at this mode.

4) To generate a voltage level $V_{\mathrm{o}}=-1 / 3 V_{\mathrm{dc}}, S_{2}$ is turned on at the negative half cycle while the energy is provided by the capacitor $C_{3}$ and the voltage across $\mathrm{H}$-bridge is $1 / 3 V_{\mathrm{dc}}$. Then the switches $S_{6}$ and $S_{7}$ are turned on and thus the voltage applied to the load terminals is $-1 / 3 V_{\mathrm{dc}}$. Fig. 6 shows the current path at this mode.

5) To generate a voltage level $V_{\mathrm{o}}=-2 / 3 V_{\mathrm{dc}}, S_{2}$ and $S_{3}$ are turned on while the energy is provided by the capacitor $C_{2}$ and $C_{3}$ and the voltage across H-bridge is $2 / 3 V_{\mathrm{dc}}$. Then the switches $S_{6}$ and $S_{7}$ are turned on and thus the voltage applied to the load terminals is $-2 / 3 V_{\mathrm{dc}}$. Fig. 7 shows the current path at this mode.
6) To generate a voltage level $V_{\mathrm{o}}=-V_{\mathrm{dc}}, S_{1}$ and $S_{2}$ are turned on while the energy is provided by the capacitor $C_{1}, C_{2}$, and $C_{3}$, the voltage across $\mathrm{H}$-bridge is $V_{\mathrm{dc}}$. Then the switches $S_{6}$ and $S_{7}$ are turned on and thus the voltage applied to the load terminals is $-V_{\mathrm{dc}}$. Fig. 8 shows the current path at this mode.

7) To generate a voltage level $V_{\mathrm{o}}=0$, switches $S_{5}$ and $S_{7}$ are turned on and thus the voltage applied to the load terminals is zero. Fig 9shows the current path at this mode.

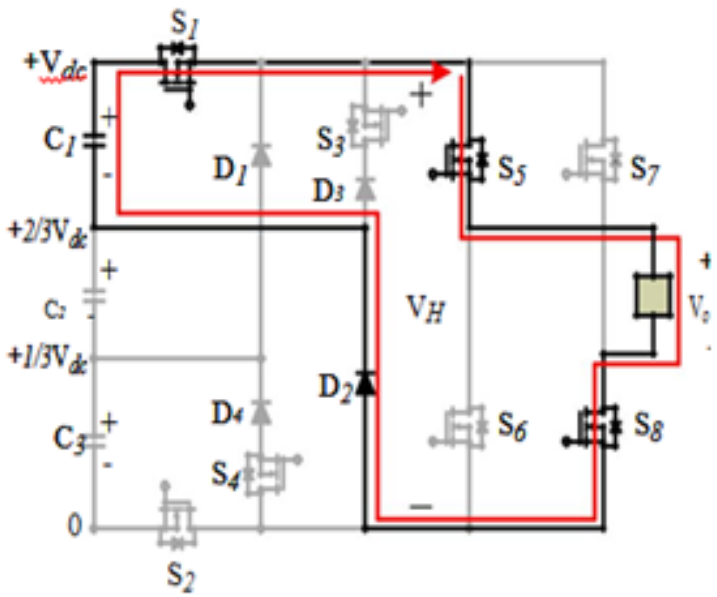

Figure 3: Switching combination of output voltage level $1 / 3 V_{\mathrm{dc}}$.

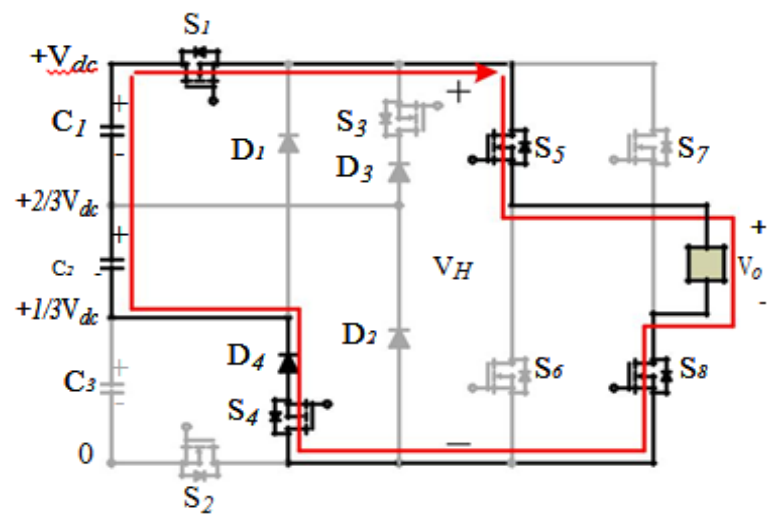

Figure 4: Switching combination of output voltage level $2 / 3 V_{\mathrm{dc}}$

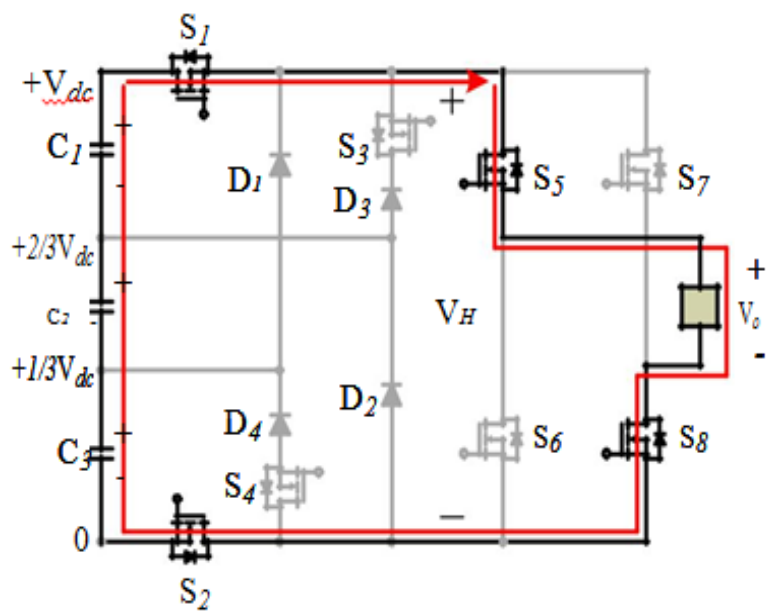

Figure 5: Switching combination of output voltage level $V_{\mathrm{d} c}$ 


\section{International Journal of Science and Research (IJSR) \\ ISSN (Online): 2319-7064}

Index Copernicus Value (2015): 78.96 | Impact Factor (2015): 6.391

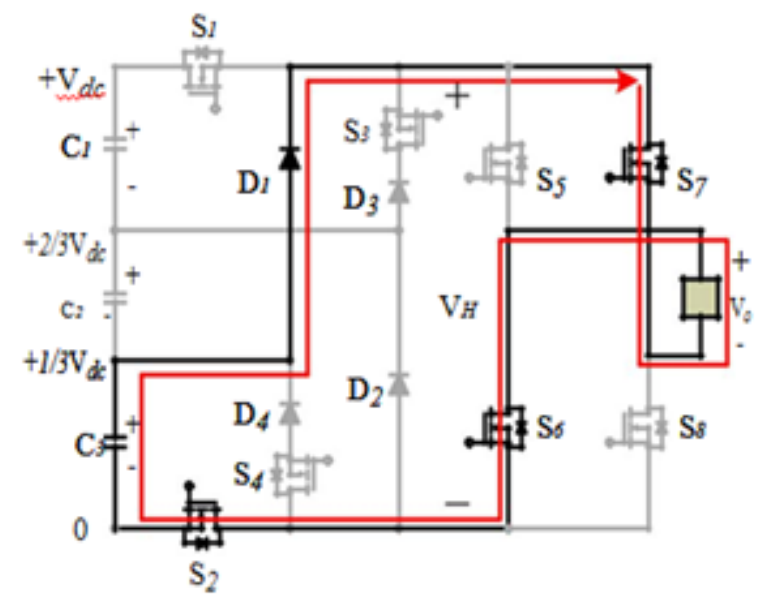

Figure 6: Switching combination of output voltage

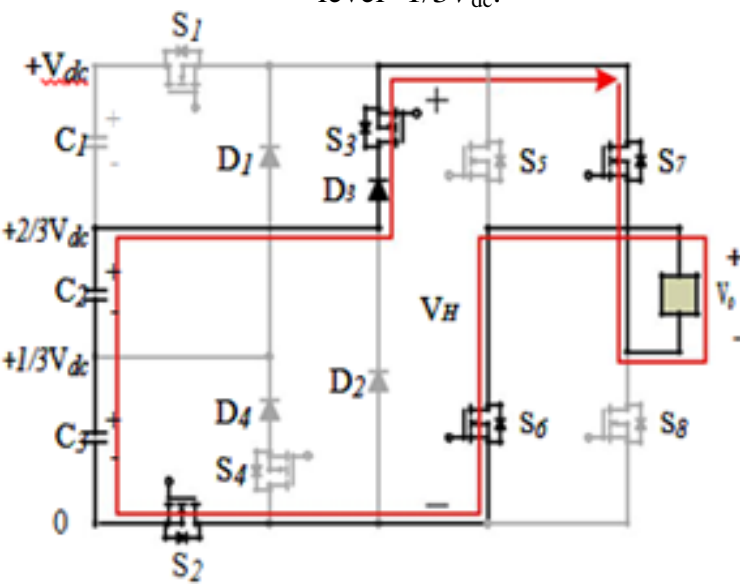

Figure 7: Switching combination of output voltage level $2 / 3 V_{\mathrm{dc}}$.

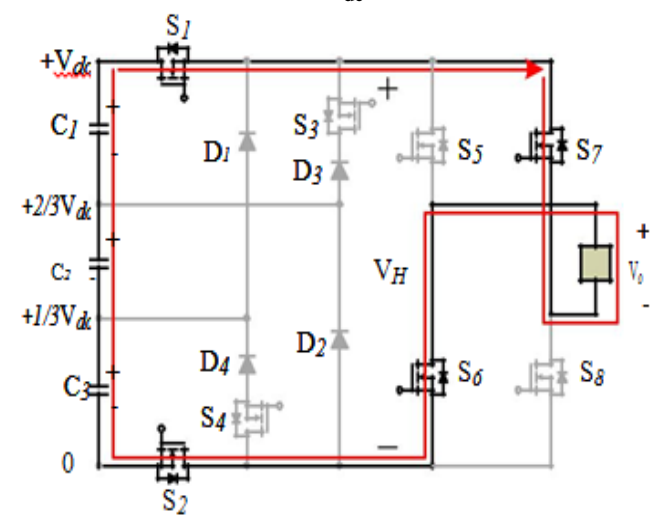

Figure 8: Switching combination of output voltage level $V_{\mathrm{dc}}$.

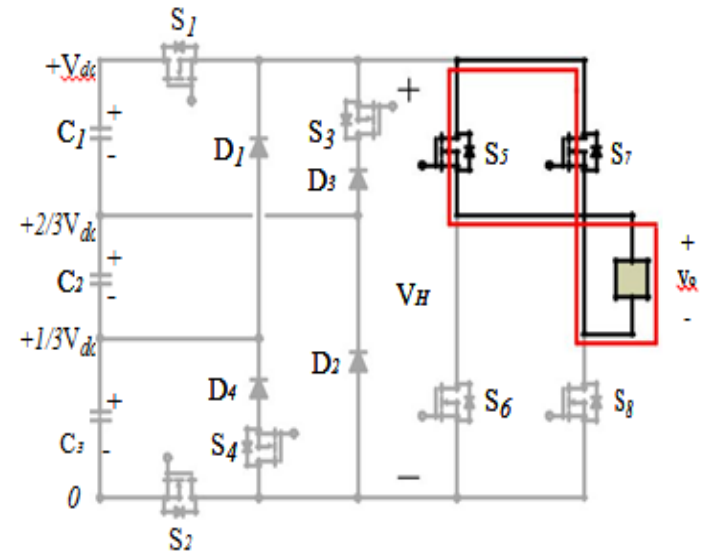

Table 1: Switching combinations required togenerate the seven-level output voltage waveform

\begin{tabular}{|c|c|c|c|c|c|c|c|c|}
\hline \multirow{2}{*}{$\begin{array}{c}\text { Output } \\
\text { voltage Vo }\end{array}$} & $S_{1}$ & $S_{2}$ & $S_{3}$ & $S_{4}$ & $S_{5}$ & $S_{6}$ & $S_{7}$ & $S_{8}$ \\
\hline $1 / 3 V_{\mathrm{dc}}$ & on & off & Off & off & On & off & off & On \\
\hline $2 / 3 V_{\mathrm{dc}}$ & on & off & Off & on & On & off & off & On \\
\hline$V_{\mathrm{dc}}$ & on & on & Off & off & On & off & off & On \\
\hline$-1 / 3 V_{\mathrm{dc}}$ & off & on & Off & off & off & on & On & Off \\
\hline$-2 / 3 V_{\mathrm{dc}}$ & off & on & On & off & off & on & On & Off \\
\hline$-V_{\mathrm{dc}}$ & on & on & Off & off & off & on & On & Off \\
\hline 0 & off & off & Off & off & On & off & On & Off \\
\hline 0
\end{tabular}

Table 2: Voltage stress comparison between four different seven level inverters

\begin{tabular}{|c|c|c|c|c|}
\hline & Proposed & $\begin{array}{l}\text { Diode- } \\
\text { clamped }\end{array}$ & $\begin{array}{l}\text { Capacitor- } \\
\text { Clamped }\end{array}$ & $\begin{array}{l}\text { Cascaded } \\
\text { multicell }\end{array}$ \\
\hline $\begin{array}{l}\text { Input } \\
\text { sources }\end{array}$ & vo & $2 \mathrm{~V}_{\mathrm{o}}$ & $2 \mathrm{~V}$ & $\mathrm{~V}_{\sigma} / 3$ \\
\hline $\begin{array}{c}\text { Input } \\
\text { capacitors }\end{array}$ & $\mathrm{V}_{2} / 3$ & $\mathrm{~V}_{d} / 3$ & $\mathrm{~V}_{d} / 2$ & $\mathrm{~V}_{d} / 3$ \\
\hline $\begin{array}{c}\text { Power } \\
\text { switches }\end{array}$ & vo & $\mathrm{V}_{0} / 3$ & $\mathrm{~V}_{\alpha} / 3$ & $\mathrm{~V}_{\sigma} / 3$ \\
\hline Diodes & $2 \mathrm{~V}_{0} / 3$ & $3 \mathrm{~V}_{0} / 2$ & $\mathrm{~N} / \mathrm{A}$ & $\mathrm{N} / \mathrm{A}$ \\
\hline
\end{tabular}

\section{Experiment Results}

A 16F877A PIC microcontroller is used to verify the proposed seven-level inverter. Table 3 shows the characteristics of the inverter. Fig 10shows the prototype of the proposed seven-level inverter.

Table 3: The specification of the proposed inverter

\begin{tabular}{|c|c|}
\hline Input voltage $V_{\text {ts }}$ & $400 \mathrm{~V}$ \\
\hline Output voltage $V_{0}$ & $220 \mathrm{~V}=$ \\
\hline Rated output porrer $P_{0}$ & $2 \mathrm{~kW}$ \\
\hline Swritching freguency $f_{5}$ & $18 \mathrm{kHz}$ \\
\hline
\end{tabular}

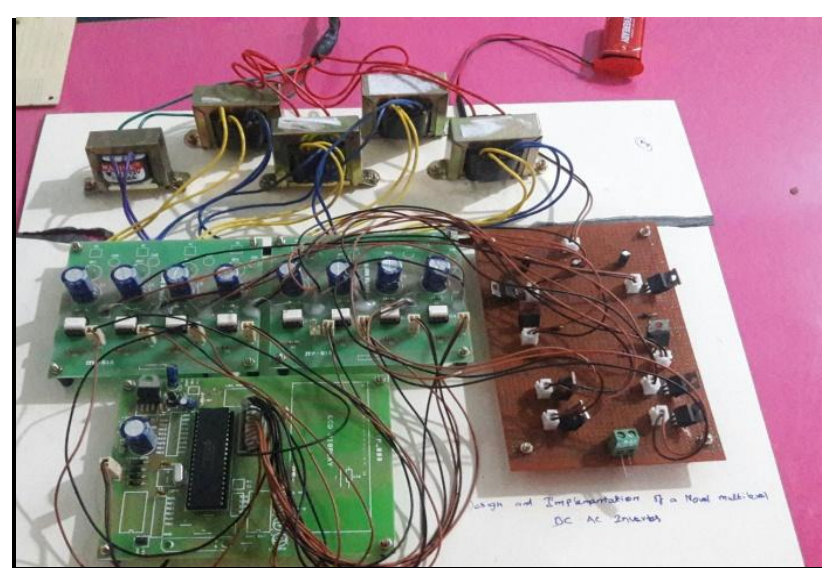

Figure 10: Experimental setup for the prototype

The efficiency at different output power is shown in Fig.11. The output power is from $200 \mathrm{~W}$ to $2000 \mathrm{~W}$. The highest efficiency is $96.9 \%$ at $800 \mathrm{~W}$, and the lowest is $94.6 \%$ at $2000 \mathrm{~W}$. The efficiency is always above $94.5 \%$.

Figure 9: Switching combination of output voltage level 0. 


\section{International Journal of Science and Research (IJSR) \\ ISSN (Online): 2319-7064}

Index Copernicus Value (2015): 78.96 | Impact Factor (2015): 6.391

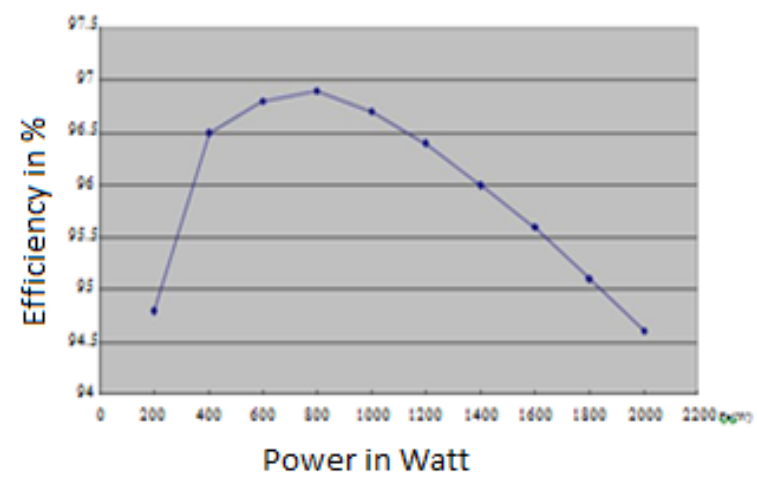

Figure 11: The efficiency of the proposed inverter

\section{Simulation Result}

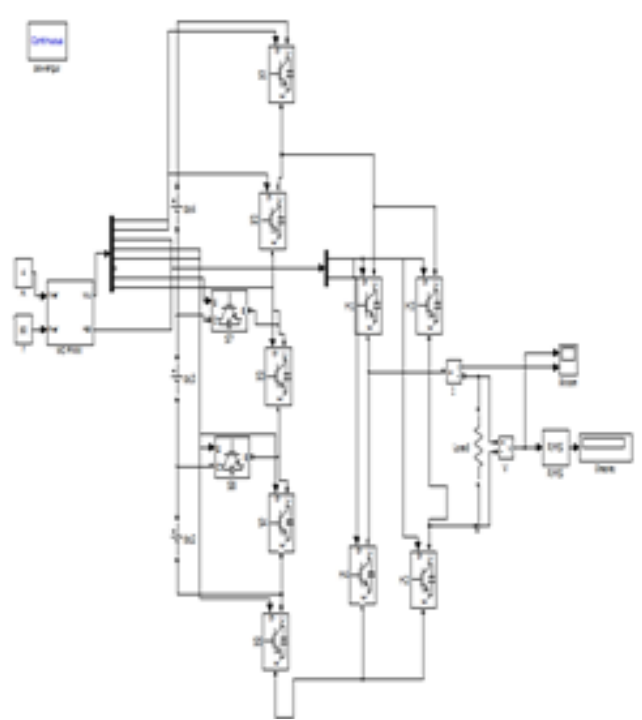

Figure 12: Simulation model for a seven level inverter

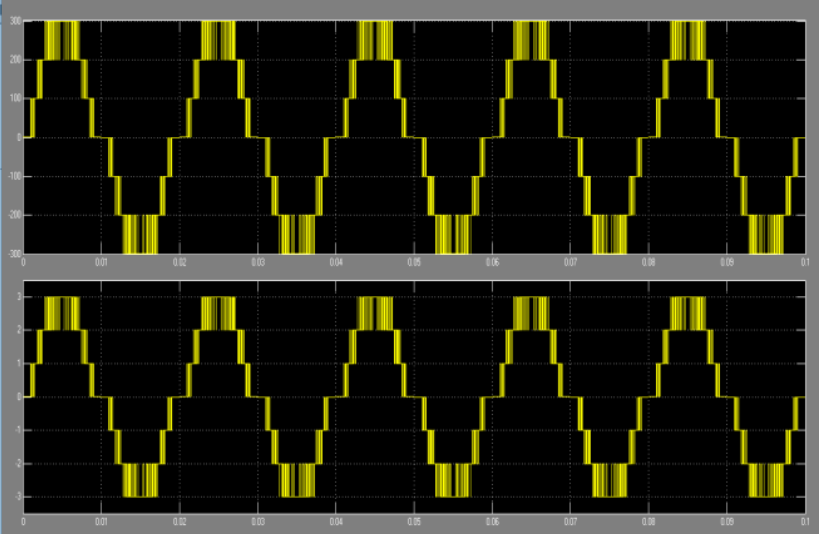

Figure 13: Output voltage and current for a seven level inverter

\section{Conclusion}

A novel seven-level inverter is designed and implemented with microcontroller in this paper. With this design the number of power devices will be reduced. The proposed system is compared with traditional structures. Finally, a laboratory model of seven-level inverter with $400 \mathrm{~V}$ input voltage and output $220 \mathrm{~V}_{\mathrm{rms}} / 2 \mathrm{~kW}$ is implemented. Experimental results show that the maximum efficiency is $96.9 \%$ and the full load efficiency is $94.6 \%$.

\section{References}

[1] R. Gonzalez, E. Gubia, J. Lopez, and L. Marroyo, "Transformerless Single-Phase Multilevel-Based Photovoltaic Inverter," IEEE Trans. on Industrial Electronics, vol. 55, no. 7, pp. 2694-2702, 2008.

[2] S. Daher, J. Schmid, and F. L. M. Antunes, "Multilevel Inverter Topologies for Stand-Alone PV Systems," IEEE Trans. on Industrial Electronics, vol. 55, no. 7, pp. 2703 2712, 2008.

[3] W. Yu, J. S. Lai, H. Qian, and C. Hutchens, "HighEfficiency MOSFET Inverter with H6-Type Configuration for Photovoltaic NonisolatedACModule Applications," IEEE Trans. on Power Electronics, vol. 26, no. 4, pp. 1253-1260, 2011.

[4] R. A. Ahmed, S. Mekhilef, and W. P. Hew, "New multilevel inverter topology with minimum number of switches," in Proc. IEEE TENCON, pp. 1862-1867, 2010.

[5] M. R. Banaei and E. Salary, "New Multilevel Inverter with Reduction of Switches and Gate Driver," in Proc. IEEE IECC, pp. 784-789, 2010.

[6] N. A. Rahim, K. Chaniago, and J. Selvaraj, "SinglePhase Seven-Level Grid-Connected Inverter for Photovoltaic System," IEEE Trans. on Industrial Electronics, vol. 58, no. 6, pp. 2435-2443, 2011.

[7] K. Hasegawa and H. Akagi, "A New DC-VoltageBalancing Circuit Including a Single Coupled Inductor for a Five-Level Diode-Clamped PWM Inverter," IEEE Trans. on Industrial Applications, vol. 47, no. 2, pp. 841852,2011

[8] T. Ito, M. Kamaga, Y. Sato, and H. Ohashi, "An Investigation of Voltage Balancing Circuit for DC Capacitors in Diode-Clamped Multilevel Inverters to Realize High Output Power Density Converters," in Proc. IEEE ECCE, pp. 3675-3682, 2010. 